\title{
Immunogenicity of antigens from the TbD1 region present in $M$. africanum and missing from "modern" M. tuberculosis: a cross- sectional study
}

\author{
Bouke C de Jong ${ }^{1,2^{*}}$, Abdulrahman Hammond ${ }^{1,3}$, Jacob K Otu', Martin Antonio', Richard A Adegbola',
} Martin O Ota ${ }^{1,2}$

\begin{abstract}
Background: Currently available tools cannot be used to distinguish between sub-species of the M. tuberculosis complex causing latent tuberculosis (TB) infection. M. africanum causes up to half of TB in West- Africa and its relatively lower progression to disease suggests the presence of a large reservoir of latent infection relative to $M$. tuberculosis.
\end{abstract}

Methods: We assessed the immunogenicity of the TbD1 region, present in M. africanum and absent from "modern" M. tuberculosis, in an ELISPOT assay using cells from confirmed M. africanum or M. tuberculosis infected TB patients without HIV infection in the Gambia.

Results: Antigens from the TbD1 region induced IFN $\gamma$ responses in only 35\% patients and did not discriminate between patients infected with M. africanum vs. M. tuberculosis, while PPD induced universally high responses.

Conclusions: Further studies will need to assess other antigens unique to $M$. africanum that may induce discriminatory immune responses.

\section{Background}

An estimated third of the world's population is latently (asymptomatically) infected with $M$. tuberculosis, of whom $5-10 \%$ will progress to TB disease in their lifetime, with higher rates of progression in immune compromised people [1]. Latent infection can be diagnosed with the tuberculin skin test, or more recently with interferon gamma release assays using $M$. tuberculosis specific antigens ESAT-6 and CFP-10 [2]. These antigens are present in members of the $M$. tuberculosis complex, except for the vaccine strain M. bovis BCG [3], $M$. microti and the Dassie bacillus.

Recent data suggest that $M$. africanum has a relatively large reservoir of latent infection that supports the $38 \%$ prevalence of active disease despite a lower rate of progression.

Better characterization of the immune responses leading either to containment or progression of latent TB

\footnotetext{
* Correspondence: bdejong@mrc.gm
'Bacterial Diseases Programme, MRC Laboratories, POB 273, Banjul, the

* Correspondence: bdejong@mrc.gm
${ }^{1}$ Bacterial Diseases Programme, MRC Laboratories, POB 273, Banjul, the Gambia
}

(c) 2010 de Jong et al; licensee BioMed Central Ltd. This is an Open Access article distributed under the terms of the Creative Commons Attribution License (http://creativecommons.org/licenses/by/2.0), which permits unrestricted use, distribution, and reproduction in any medium, provided the original work is properly cited.

infection to disease by M. africanum or M. tuberculosis requires diagnosis of these organisms at the latent stage of infection. During latent TB infection, the bacterial load is estimated to be low, and the location of the persistent bacteria is unknown. Molecular genotyping methods rely on the isolation of bacterial DNA, which is currently not possible from patients with latent TB infection. Nevertheless, the persistent bacteria induce an immune response that can be assessed in the periphery [1].

The TbD1 region is present in $M$. africanum but absent in "modern" M. tuberculosis [3]. M. bovis has not yet been isolated from humans or bovines in the Gambia [4,5], and "ancient" $M$. tuberculosis causes only $3.4 \%$ of TB in the Gambia [6].

Therefore we hypothesized that a response to TbD1 antigens should be relatively specific for $M$. africanum, which could subsequently be used to determine the prevalence of latent infection with $M$. africanum. We tested the sensitivity and specificity of these TbD1 antigens in an ex-vivo IFN- $\gamma$ ELISPOT assay in TB cases infected with $M$. africanum or M. tuberculosis. 


\section{Methods}

After informed consent, adult patients with smear positive TB were recruited in an ongoing TB Case Contact study in the Gambia and offered Voluntary Counseling and Testing for HIV as described previously [2]. This study was approved by the joint Gambian Government/ MRC ethics committee and by the IRB from New York University. HIV infected patients were excluded from this analysis.

\section{Synthetic peptides}

Antigens were prepared from TbD1, a region missing from "modern" M. tuberculosis and present in M. africanum and $M$. bovis [3]. TbD1 contains 2 genes, mmpL6 and mmpS6, of which mmpL6 was prepared as 2 separate peptides, mmpL6-C and mmpl6-N. Due to constraints in the number of cells, we initially screened these two peptides from mmpL6 in separate wells in ELISPOT, and later selected mmpL6-C together with mmpS6 as test antigens.

\section{RD-1 and TbD1 antigens in ex vivo IFN $\gamma$ ELISPOT}

We used an ex vivo ELISPOT technique to enumerate frequencies of circulatory IFN $\gamma$-producing $\mathrm{T}$ cell responses as shown previously [2]. Briefly, peripheral blood mononuclear cells (PBMC) were isolated from 15 $\mathrm{ml}$ heparinized whole blood and resuspended in RPMI1640 culture media supplemented with $100 \mathrm{IU} / \mathrm{ml}$ penicillin, $100 \mu \mathrm{g} / \mathrm{ml}$ streptomycin, $5 \%$ heat-inactivated AB human serum (Sigma), and $2 \mathrm{mM}$ L-glutamine. The cells were then plated in duplicate at $2 \times 10^{5}$ per well, and cultured for $18 \mathrm{~h}$ at $37^{\circ} \mathrm{C}$ with the following antigens: medium alone, ESAT-6 peptide pool (EP, $2.5 \mu \mathrm{g} /$ $\mathrm{ml})$, CFP-10 peptide pool (CP, $2.5 \mu \mathrm{g} / \mathrm{ml})[2,7,8]$, ESAT6/CFP-10 fusion protein (FP, $5 \mu \mathrm{g} / \mathrm{ml}$ ), PPD-tuberculin (PPD-T [M. tuberculosis, RT49; Statens serum Institut, Copenhagen, Denmark], $20 \mu \mathrm{g} / \mathrm{ml}$ ), peptides corresponding to TbD1 antigen (prepared by C. Franken, 10 $\mu \mathrm{g} / \mathrm{ml}$ ), and PHA (Sigma-Aldrich, $5 \mu \mathrm{g} / \mathrm{ml}$ ) that served as a positive control. The ELISPOT plates were developed following the manufacturer's instructions and spot forming units (SFU) were scored with an automated ELISPOT counter (AID-GmBH, Strasbourg, Germany). A positive response (cut-off) was recorded if SFU were $\geq 8$ spots above background and there were twice as many spots as negative control wells. Data were excluded if PHA positive control wells were $<150$ spots [7-9].

\section{Laboratory isolates and genotyping}

All TB cases submitted sputum for conventional mycobacteriology, including Acid Fast smears and cultures in liquid and solid media as described previously [6]. By genotyping the isolates from these patients using spoligotyping [10], we classified the patients as infected with M. africanum or M. tuberculosis [5].

\section{Statistical analysis}

We used Stata software (version 10; Stata-Corp) and performed the non-parametric Mann-Whitney test to compare continuous variables, considering $P<0.05$ as statistically significant.

\section{Results}

\section{Patient and isolate characteristics}

We enrolled 81 TB patients, of whom 74 (91\%) agreed with HIV testing, including nine who tested positive (12.2\%, eight with HIV-1 and one with HIV-2). Of the 65 HIV negative TB patients, one patient had uninterpretable ELISPOT results, two did not have a genotyped bacterial isolate, and 62 (77\%) patients were included in the analysis. Both mmpL6-C and mmpL6-N peptides were tested in 24 patients, while mmpL6-C peptide alone was tested in combination with the mmpS6 peptide in 38 patients. TB disease was caused by $M$. africanum in 21 (34\%) of the patients, with the remainder due to $M$. tuberculosis, including $3(4.8 \%)$ "ancient" $M$. tuberculosis isolates with intact $\mathrm{TbD} 1$ region.

\section{Immunogenicity of $M$. africanum specific peptides}

The mmpL6-C peptide induced IFN $\gamma$ responses in $19 \%$ of $M$. africanum infected cases, the mmpL6-N peptide in $17 \%$, and the mmpS6 peptide in $20 \%$. The proportion who responded to any of the three TbD1 antigens was similar between $M$. africanum infected patients and M. tuberculosis infected patients (respectively $33 \%$ and $37 \%, \mathrm{p}=0.80$ ). Equal numbers of patients infected with $M$. africanum and with $M$. tuberculosis responded to PPD (respectively 95\% and $90 \%, \mathrm{p}=0.49$ ), whereas responses to ESAT-6, CFP-10 and ESAT-6/CFP-10 fusion protein tended to be lower in M. africanum infected patients (Figure 1 ).

Of the three patients infected with "ancient" $M$. tuberculosis, one responded to TbD1 antigens and two did not. The results did not change significantly with the inclusion or exclusion of these cases as M. tuberculosisinfected in the analysis.

\section{Discussion}

To our knowledge, this study is the first attempt at uncovering $\mathrm{TB}$ sub-species specific $\mathrm{T}$ cell responses in the natural human host. Our findings suggest that the antigens prepared from TbD1 do not induce a robust $\mathrm{T}$ cell response in humans. Among the responders, there was moreover no difference in TbD1 recognition between the proportion of patients infected with "modern" $M$. tuberculosis, which lacks the TbD1 region, and the proportion infected with $M$. africanum, with an intact $\mathrm{TbD} 1$ region. Lastly, we identified a trend towards attenuated immunogenicity of ESAT- 6 and CFP-10 in $M$. africanum infected TB cases, on which we reported previously [11]. 


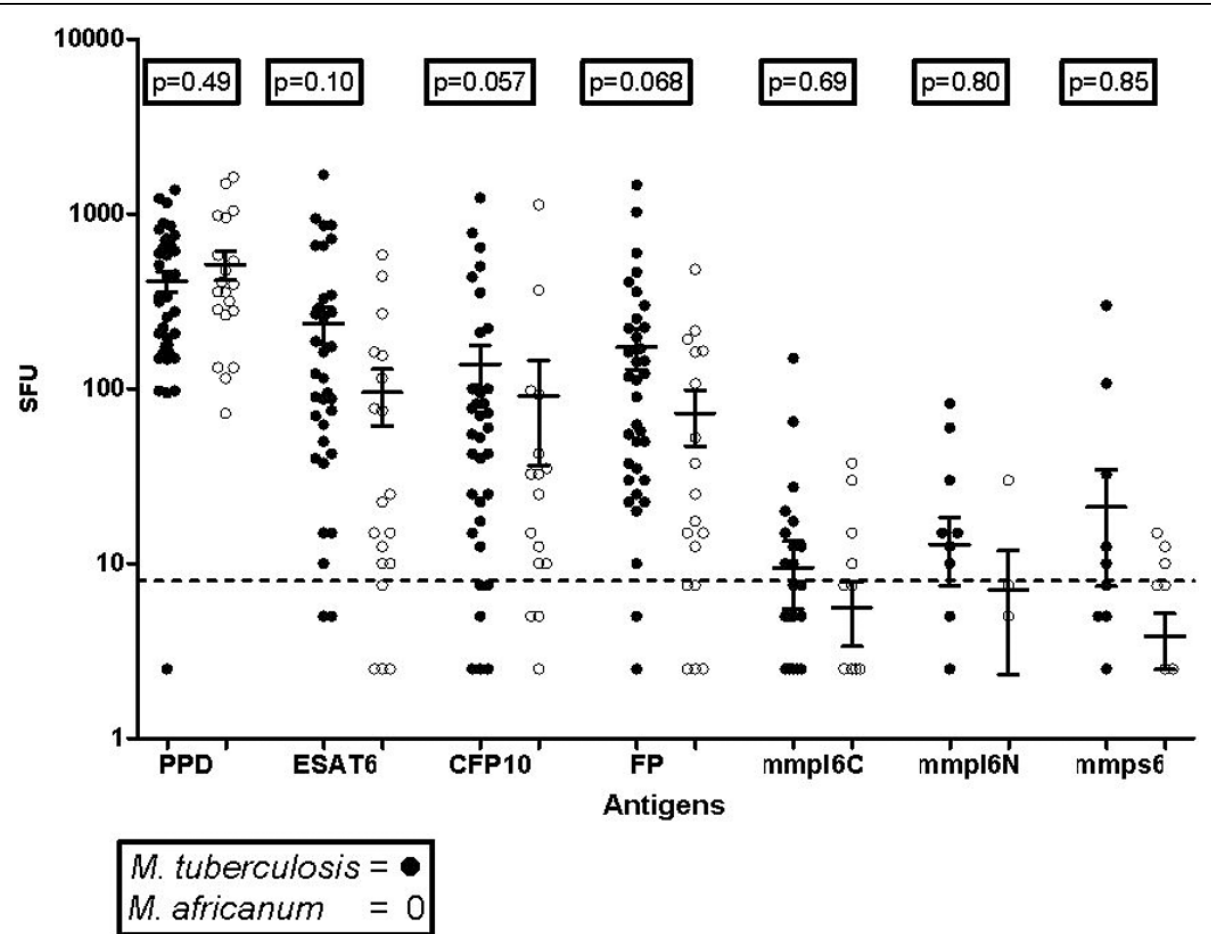

Figure 1 Differences in ELISPOT responses between TB casesinfected with $\boldsymbol{M}$. tuberculosis versus $\boldsymbol{M}$. africanum. The TbD 1 based antigens mmpl6C, mmpl6N, and mmps6 did not induce robust responses in M. africanum infected patients, despite the presence of an intact TbD1 region in $M$. africanum. The horizontal lines indicate the mean and SEM. FP = ESAT-6/CFP-10 fusion protein.

The low proportion of responders may be due to poor host recognition of these antigens, or due to the fact that the host response includes cytokines other than IFN $\gamma$ or B cell rather than $\mathrm{T}$ cell responses. Indeed, mmpL6 is a putative transmembrane transport protein [12] and may induce a B cell response against its extracellular tail.

Although we did not identify instances of dual infection from the cultured sputum samples, the presence of dual infection could explain the inability of the TbD1 antigens to discriminate between those diseased with $M$. africanum from $M$. tuberculosis. Undetected dual infection in TB patients could occur when one organism was maintained in latency while the other caused TB disease, or when both organisms partook in active TB disease, but one organism outgrew the other in culture. The latter can be addressed by genotyping the isolates with species-specific primers using DNA extracted from sputum samples.

The $M$. africanum whole genome sequencing project is near completion, which will facilitate the search for other discriminatory antigens unique to $M$. africanum. The TbD1 region, shared by $M$. africanum and $M$. bovis, is the only region identified in the $M$. bovis genome that is absent from M. tuberculosis, so our findings may also inform veterinary research directed at distinguishing M. bovis- vs "modern" M. tuberculosis specific responses in latently infected cows.

\section{Conclusions}

In conclusion, assessment of the prevalence of TB latency with one or more different sub-species within the M. tuberculosis complex will depend on the detection of specific host responses, due to inability to extract mycobacterial DNA from latently infected individuals. The TbD1 region, which is absent in "modern" $M$. tuberculosis and present in M. africanum and M. bovis, does not induce a discriminatory IFN $\gamma \mathrm{T}$ cell response in TB patients in the Gambia. Further studies will need to assess whether $\mathrm{TbD} 1$ induces $\mathrm{B}$ cell responses, which would facilitate assessment of the prevalence of latent infection with distinct sub-species. Alternatively, the whole genome sequence may reveal other antigens unique to $M$. africanum that may induce T cell- and/or $B$ cell responses.

\section{Acknowledgements}

We thank Michel Klein and Cees Franken for the mmpL6 and mmpS6 antigens, the TB patients and their contacts for their participation in the study, and Neneh Sallah for her help in genotyping the isolates. The study was funded by the Medical Research Council, the Gambia, and BCD was supported by the National Institutes of Health (NIH), grant K01-TW006083. The study sponsors had no involvement in the study design, in the 
collection, analysis and interpretation of data; in the writing of the manuscript; and in the decision to submit the manuscript for publication.

\section{Author details}

'Bacterial Diseases Programme, MRC Laboratories, POB 273, Banjul, the Gambia. ${ }^{2}$ New York University, 550 First Avenue, Smilow 901, New York, NY 10016, USA. ${ }^{3}$ FMPOS, University of Bamako, Point G, Bamako, Mali.

\section{Authors' contributions}

B CJ conceived of the study, carried out the genotyping studies, performed the statistical analysis and drafted the manuscript. AH carried out the immunoassays and helped to draft the manuscript. JO conducted the mycobacterial studies. MA coordinated mycobacterial studies and molecular analysis. RAA participated in study design and coordination. MOO participated in study design and coordination and helped to draft the manuscript. All authors read and approved the final manuscript.

\section{Competing interests}

The authors declare that they have no competing interests.

Received: 2 June 2009

Accepted: 19 January 2010 Published: 19 January 2010

\section{References}

1. Corbett EL, Watt CJ, Walker N, Maher D, Williams BG, Raviglione MC, Dye C: The growing burden of tuberculosis: global trends and interactions with the HIV epidemic. Arch Intern Med 2003, 163(9):1009-1021.

2. Hill PC, Brookes RH, Fox A, Fielding $K$, Jeffries DJ, Jackson-Sillah D, Lugos MD, Owiafe PK, Donkor SA, Hammond AS, et al: Large-scale evaluation of enzyme-linked immunospot assay and skin test for diagnosis of Mycobacterium tuberculosis infection against a gradient of exposure in The Gambia. Clin Infect Dis 2004, 38(7):966-973.

3. Brosch R, Gordon SV, Marmiesse M, Brodin P, Buchrieser C, Eiglmeier K, Garnier T, Gutierrez C, Hewinson G, Kremer K, et al: A new evolutionary scenario for the Mycobacterium tuberculosis complex. Proc Natl Acad Sci USA 2002, 99(6):3684-3689.

4. Unger F, Münstermann S, Goumou A, Apia CN, Konte M: Risk associated with Mycobacterium bovis infections detected in selected study herds and slaughter cattle in 4 countries of West Africa. Animal Health Working Paper 1 Banjul: ITC (International Trypanotolerance Centre) 2003, 1-25.

5. de Jong BC, Hill PC, Aiken A, Jeffries DJ, Onipede A, Small PM, Adegbola RA, Corrah TP: Clinical presentation and outcome of tuberculosis patients infected by M. africanum versus M. tuberculosis. Int J Tuberc Lung Dis 2007, 11(4):450-456.

6. de Jong BC, Antonio M, Awine T, Ogungbemi K, de Jong YP, Gagneux S, Deriemer K, Zozio T, Rastogi N, Borgdorff M, et al: Use of spoligotyping and large-sequence polymorphisms to study the population structure of the Mycobacterium tuberculosis complex in a cohort study of consecutive smear positive tuberculosis cases in the Gambia. I Clin Microbiol 2009, 47(4):994.

7. Hill $P C$, Jackson-Sillah $D$, Fox $A$, Franken $K L$, Lugos $M D$, Jeffries DJ, Donkor SA, Hammond AS, Adegbola RA, Ottenhoff TH, et al: ESAT-6/CFP-10 fusion protein and peptides for optimal diagnosis of mycobacterium tuberculosis infection by ex vivo enzyme-linked immunospot assay in the Gambia. J Clin Microbiol 2005, 43(5):2070-2074

8. Hill PC, Fox A, Jeffries DJ, Jackson-Sillah D, Lugos MD, Owiafe PK, Donkor SA, Hammond AS, Corrah T, Adegbola RA, et al: Quantitative T cell assay reflects infectious load of Mycobacterium tuberculosis in an endemic case contact model. Clin Infect Dis 2005, 40(2):273-278.

9. Jeffries DJ, Hill PC, Fox A, Lugos M, Jackson-Sillah DJ, Adegbola RA, Brookes RH: Identifying ELISPOT and skin test cut-offs for diagnosis of Mycobacterium tuberculosis infection in The Gambia. Int I Tuberc Lung Dis 2006, 10(2):192-198.

10. Kamerbeek J, Schouls L, Kolk A, van Agterveld M, van Soolingen D, Kuijper S, Bunschoten A, Molhuizen H, Shaw R, Goyal M, et al: Simultaneous detection and strain differentiation of Mycobacterium tuberculosis for diagnosis and epidemiology. J Clin Microbiol 1997, 35(4):907-914.

11. de Jong BC, Hill PC, Brookes RH, Gagneux S, Jeffries DJ, Otu JK, Donkor SA, Fox A, McAdam KP, Small PM, et al: Mycobacterium africanum Elicits an Attenuated T Cell Response to Early Secreted Antigenic Target, 6 kDa, in
Patients with Tuberculosis and Their Household Contacts. J Infect Dis 2006, 193(9):1279-1286.

12. Bovilist. http://genolist.pasteur.fr/BoviList/.

\section{Pre-publication history}

The pre-publication history for this paper can be accessed here:http://www. biomedcentral.com/1471-2334/10/11/prepub

doi:10.1186/1471-2334-10-11

Cite this article as: de Jong et al:: Immunogenicity of antigens from the TbD1 region present in $M$. africanum and missing from "modern" $M$. tuberculosis: a cross- sectional study. BMC Infectious Diseases 2010 10:11.

\section{Publish with Biomed Central and every scientist can read your work free of charge}

"BioMed Central will be the most significant development for disseminating the results of biomedical research in our lifetime. "

Sir Paul Nurse, Cancer Research UK

Your research papers will be:

- available free of charge to the entire biomedical community

- peer reviewed and published immediately upon acceptance

- cited in PubMed and archived on PubMed Central

- yours - you keep the copyright
BioMedcentral 